\title{
Oncology Nurses' Obstacles and Supportive Behaviors in End-of- Life Care: Providing Vital Family Care
}

\author{
Renea L. Beckstrand \\ Brigham Young University - Provo \\ Joan Collette \\ Lynn Callister \\ Brigham Young University - Provo \\ Karlen E. (Beth) Luthy \\ Brigham Young University - Provo, beth_luthy@byu.edu \\ Follow this and additional works at: https://scholarsarchive.byu.edu/facpub \\ Part of the Critical Care Nursing Commons, and the Other Nursing Commons
}

\section{Original Publication Citation}

Beckstrand, R. L., Collett, J.**, Callister, L. C., \& Luthy, K. E. (2012). Oncology nurses' obstacles and supportive behaviors in end-of-life care: Providing vital family care. Oncology Nursing Forum, 39(5), e398-e406.

\section{BYU ScholarsArchive Citation}

Beckstrand, Renea L.; Collette, Joan; Callister, Lynn; and Luthy, Karlen E. (Beth), "Oncology Nurses' Obstacles and Supportive Behaviors in End-of-Life Care: Providing Vital Family Care" (2012). Faculty Publications. 5234.

https://scholarsarchive.byu.edu/facpub/5234

This Peer-Reviewed Article is brought to you for free and open access by BYU ScholarsArchive. It has been accepted for inclusion in Faculty Publications by an authorized administrator of BYU ScholarsArchive. For more information, please contact ellen_amatangelo@byu.edu. 


\title{
Oncology Nurses' Obstacles and Supportive Behaviors in End-of-Life Care: Providing Vital Family Care
}

\author{
Renea L. Beckstrand, PhD, RN, CCRN, CNE, Joan Collette, MS, FNP-c, \\ Lynn Callister, PhD, RN, FAAN, and Karlen E. Luthy, DNP, FNP-C
}

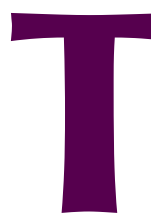

he need for effective and compassionate end-of-life (EOL) care grows more critical as the number of people predicted to get cancer is expected to increase in every region of the world (Bray, Jemal, Grey, Ferlay, $\&$ Forman, 2012). Cancer is the second leading cause of death in the United States overall and the leading cause of death in people aged 45-64 (Kochanek, Xu, Murphy, Miniño, \& Kung, 2011). In 2012, an estimated 577,190 Americans will die of cancer (Bray et al., 2012). In the United States, although most people would prefer to die at home, 56\% die in the hospital (Cassel \& Demel, 2001). These statistics reinforce the reality that hospitalbased oncology nurses are at the forefront of healthcare providers who care for dying patients.

In 2010, the Oncology Nursing Society (ONS) and Association of Oncology Social Work issued a joint position statement outlining the importance of providing high-quality palliative EOL care. The American Society for Pain Management Nursing (2003) also issued a position statement on EOL care, which stated that comprehensive and compassionate EOL care was the responsibility of nurses.

Nurses regularly care for patients who are in the final stages of life and can identify behaviors that obstruct or improve EOL care for patients and families (Pavlish \& Ceronsky, 2009). More than $30 \%$ of patients diagnosed with cancer will die from the disease (American Cancer Society, 2012); therefore, identifying the obstacles or supportive behaviors that have the most impact to patients and families and then working to eliminate highly rated obstacles or increase support for positive behaviors is critical to improve EOL care.

\section{Literature Review}

In 1995, investigators found major shortfalls in the care of dying adults hospitalized in the United
Purpose/Objectives: To determine the impact of obstacles and supportive behaviors in end-of-life (EOL) care as perceived by hospital-based oncology nurses.

Design: A 69-item mailed survey.

Setting: National random sample.

Sample: 1,005 nurse members of the Oncology Nursing Society who had provided EOL care for patients with cancer.

Methods: Three mailings yielded 380 usable responses from 912 eligible respondents, resulting in a $42 \%$ return rate.

Main Research Variables: Size and frequency of EOL care obstacles and supportive behaviors for patients with cancer in a hospital setting.

Findings: Results of this research demonstrate the need for more EOL education and help in forming teams of nurses, social and palliative care workers, and physicians to support high-quality care. Another finding was the need for other nurses at a facility to give the nurse caring for the dying patient more time to support the patient and family.

Conclusions: Dealing with the family is vital in providing optimal EOL care to patients dying from cancer. By carefully listening to the experience, concerns, and recommendations of hospital-based oncology nurses, compassionate EOL care can be provided to these patients and their families.

Implications for Nursing: Oncology nurses are dedicated to providing the best EOL care to their patients and patients' families. This study helped to identify research-based obstacles and supportive behaviors regarding the provision of high-quality EOL care.

States during observation of more than 9,000 patients (SUPPORT Principal Investigators, 1995). The SUPPORT study showed a significant deficiency in communication of patients' desires for EOL care to their healthcare team and shortcomings in frequency of aggressive treatment and other characteristics of death in hospitals, such as do-not-resuscitate (DNR) orders being written within two days of the patient dying or family members reporting that half the time 
of their hospital stay their dying family members experienced moderate to severe pain (SUPPORT Principal Investigators, 1995). Hoping to improve patient-family-physician communication that could lead to better EOL care, a SUPPORT phase II intervention was developed; however, no improvement was seen in communication of the wants and needs of hospitalized patients regarding EOL care or in the other five target outcomes, such as timing of written DNR orders related to time of death (SUPPORT Principal Investigators, 1995).

The SUPPORT study illustrated that the American healthcare system has not been successful in providing the type of care where palliative rather than curative services are needed, providing comfort over cure (Rutledge, Donaldson, \& Pravikoff, 2001). Since SUPPORT, other studies have attempted to identify obstacles and supportive behaviors and other interventions to increase the quality of EOL care in the United States and globally (Beckstrand, Smith, Heaston, \& Bond, 2008; Beckstrand, Callister, \& Kirchhoff, 2006; Coyne et al., 2007; Heyland et al., 2006; Singer \& Bowman, 2002; Steinhauser et al., 2000; Yabroff, Mandelblatt, \& Ingham, 2004). Although those studies add to the body of knowledge regarding EOL care, more data are needed regarding oncology nurse perceptions of obstacles and supportive behaviors in EOL care.

In the literature review conducted for this study, three needs were identified: (a) better and more frequent communication between the patient, family, and healthcare team, as well as between healthcare team members, (b) more time for nurses to perform EOL care, and (c) high-quality EOL training for oncology nurses.

\section{The Need for Communication}

Multiple studies in EOL care identified good communication as important to patients, families, and oncology nurses. Albinsson and Strang (2003) asked 121 participants in a national course on palliative cancer care to define the two most important measures to support families of severely ill patients with cancer. Listening was identified as important by $65 \%$ of participants and giving information was identified by $52 \%$.

Royak-Schaler et al. (2006) explored communication regarding EOL care from the perspective of family members of dying patients with cancer and concluded that EOL care satisfaction was associated closely with how the family perceived the quality of communication from the healthcare team. The study reported that families wanted timely and accurate information to make informed decisions about EOL care.

In a study conducted by White, Coyne, and Patel (2001), oncology nurses ranked how to communicate with dying patients and their families as the number one EOL competency they would have liked more education about while in nursing school. Therefore, families and nurses agree that good communication is crucial to providing high-quality oncology EOL care.

A qualitative study of 33 hospital oncology nurses by Pavlish and Ceronsky (2009) identified five key nursing roles in providing palliative care at EOL (teaching, caring, coordinating, advocating, and mobilizing), which all had communication as a common theme. The roles of teaching, caring, and mobilizing required communication specifically between nurse and the patient and family, whereas the roles of coordinating and advocating required communication with all members of the healthcare team.

\section{The Need for Time}

Nurses reported that adequate time was necessary to provide high-quality EOL care. Albinsson and Strang (2003) found issues relating to time were lack of nurse availability and providing support. Availability required "being there" for the patient and creating a sense of security for anxious family members through behaviors such as listening and taking time with them. Providing support involved showing empathy to and providing support for the family at the time of death. Cramer (2010) also reported the importance of having the time to be there for the patient and family and referred to it as the power of presence.

In a study of 33 oncology nurses at a midwestern healthcare service organization, Pavlish and Ceronsky (2007) explored nurses' perceptions about the context of palliative care. The most frequent concern in the acute care setting was the limited time available to give compassionate and comprehensive palliative care. Nurses also reported being torn between time demands of palliative care and the emotions accompanying involvement with the patient and family at the EOL.

\section{The Need for End-of-Life Training}

The third identified theme was the need for and lack of EOL training for oncology nurses. Braun, Gordon, and Uziely (2010) found that nurses' personal attitudes toward death affected their care of dying patients. They concluded that training should include discussions of attitudes toward death, such as death avoidance and fear of death. Lange, Thom, and Kline (2008) assessed nursing attitudes in a cancer care center in New York, NY, and found that oncology nurses had a generally positive attitude toward death, but the most positive attitudes were present in the more experienced nurses. Implementing educational programs taught by experienced nurses offered less experienced nurses the knowledge they needed to offer better EOL care. 


\section{Obstacles and Supportive Behaviors}

Beckstrand, Moore, Callister, and Bond (2009) reported oncology nurses' perceptions of the size of obstacles and helpful or supportive behaviors at the EOL. The three largest obstacles were (a) having to deal with angry family members, (b) families not accepting what the physician is telling them about the patient's poor prognosis, and (c) being called away from the patient and family because of the need to help with a new admission or to help other nurses care for their patients. The three largest supportive behaviors were (a) allowing family members adequate time to be alone with the patient after he or she has died, (b) having social work or palliative care as part of the patient care team, and (c) having family members accept that the patient is dying. No frequency of occurrence data were included in the report, so it was not clear whether those highly rated obstacles or supportive behaviors also occurred frequently.

Oncology nurses' perceptions of the size of obstacles and supportive behaviors were published previously (Beckstrand et al., 2009). Information from oncology nurses about obstacle and supportive behavior item size, along with frequency of occurrence data, could help reveal current priorities in EOL care. The purpose of this study was to add frequency of occurrence data to obstacle and supportive behavior item size to determine individual item impact scores. The research questions were (a) what do oncology nurses perceive to be the largest and most frequently occurring obstacles to providing high-quality EOL care, and (b) what do oncology nurses perceive to be the largest and most frequently occurring supportive behaviors to providing high-quality EOL care?

\section{Methods}

\section{Sample}

Following institutional review board approval from Brigham Young University, a national, random, geographically dispersed sample of 1,000 oncology nurses was obtained from ONS. Inclusion criteria for participants included having cared for at least one hospitalized patient with cancer at the EOL and the ability to read and understand English. Consent to participate was assumed on return of the questionnaire.

\section{Instruments}

The questionnaire used was adapted from two similar studies with critical care nurses (Beckstrand \& Kirchhoff, 2005) and emergency room nurses (Beckstrand et al., 2008). After information was gathered from literature and expert opinion, revisions were made to more closely apply the questionnaire to oncology
EOL care. The questionnaire then was piloted with 28 experienced oncology nurses from three hospitals in one western state. The final questionnaire contained 68 items, including 50 Likert-type items, 4 open-ended questions, and 14 demographic questions. Data reporting oncology nurses' perceptions of EOL care were published (Beckstrand et al., 2009).

Participants were asked to rate obstacle and supportive behavior items on two criteria, size and frequency of occurrence. Items were rated on a size scale ranging from 0 (not an obstacle or supportive behavior) to 5 (an extremely large obstacle or supportive behavior) and a frequency scale ranging from 0 (never occurs) to 5 (always occurs). After the questionnaires were returned, results were entered into SPSS ${ }^{\circledast}$, version 18.0. Mean scores for obstacle items and supportive behavior items on size and frequency of occurrence then were calculated. The size mean score and frequency mean score for each individual item were multiplied to yield an impact score (Sawatzky, 1996) for each obstacle and supportive behavior item. Items then were ranked from highest to lowest impact score to determine which obstacle and supportive behavior items were perceived to have the greatest impact.

\section{Results}

After three mailings to 1,005 potential participants, 93 questionnaires were eliminated from the study because they were undeliverable $(n=4)$, the nurse was retired $(n=4)$, or respondents reported they were ineligible $(\mathrm{n}=85)$. The return yielded 380 usable questionnaires from 912 eligible respondents, for a return rate of $42 \%$. Of those in the sample who reported gender, most were women. The median age of respondents was 48 years, with a range of $23-72$ years (see Table 1 ). In addition, 68\% reported being an Oncology Certified Nurse $\left(\mathrm{OCN}^{\circledR}\right)$, Advanced Oncology Certified Nurse $\left(\mathrm{AOCN}^{\circledR}\right)$, or Certified Pediatric Oncology Nurse $\left(\mathrm{CPON}^{\circledR}\right)$ at some point in their career.

\section{Obstacles}

Participants rated 26 obstacle items for size and frequency of occurrence, which yielded perceived obstacle impact scores (POIS) ranging from 0.592-11.48 (see Table 2). The highest-ranked obstacle was dealing with anxious family members. Obstacle items ranked second and fourth were similar in context: family not accepting patient's poor prognosis and families being overly optimistic despite the patient's poor prognosis. The obstacle item ranked third was being called away from the patient and family because of the need to help with a new admission or to help other nurses care for their patients. The lowest-scored items were no social work or 
clergy support person, pressure to limit grieving time after a patient's death to accommodate a new admission, and restrictive visiting hours.

\section{Table 1. Demographic Characteristics}

\begin{tabular}{lcrc}
\hline Characteristic & $\overline{\mathbf{X}}$ & SD & Range \\
\hline Age (years) & \multicolumn{1}{c}{48} & 10.7 & $23-72$ \\
Years as RN & 17.9 & 11.1 & $1.5-45$ \\
Years in oncology & 12.5 & 8.3 & $1-40$ \\
Hours worked per week $_{\text {Number of beds in oncology unit }}$ & 36.2 & 10.4 & $0-80$ \\
Years as OCN $^{\circledR}$ & 28.3 & 11.6 & $0-100$ \\
Years as AOCN $^{\circledR}$ & 7.3 & 5.6 & $0.5-25$ \\
\hline
\end{tabular}

\begin{tabular}{|c|c|c|}
\hline Characteristic & $\mathbf{n}$ & $\%$ \\
\hline \multicolumn{3}{|l|}{ Gender } \\
\hline Female & 355 & 93 \\
\hline Male & 18 & 5 \\
\hline No response & 7 & 2 \\
\hline \multicolumn{3}{|l|}{ Number of dying patients cared for } \\
\hline More than 30 & 258 & 68 \\
\hline $21-30$ & 29 & 8 \\
\hline $11-20$ & 48 & 13 \\
\hline $5-10$ & 26 & 7 \\
\hline Fewer than 5 & 13 & 3 \\
\hline No response & 6 & 2 \\
\hline \multicolumn{3}{|l|}{ Highest degree } \\
\hline Nursing diploma & 29 & 8 \\
\hline Associate's & 84 & 22 \\
\hline Bachelor's & 184 & 48 \\
\hline Master's & 72 & 19 \\
\hline Doctoral & 5 & 1 \\
\hline No response & 6 & 2 \\
\hline \multicolumn{3}{|l|}{ Ever certified as $\mathrm{OCN}^{\circledR}$ or $\mathrm{AOCN}^{\circledR}$} \\
\hline Yes & 245 & 65 \\
\hline No & 118 & 31 \\
\hline No response & 17 & 5 \\
\hline \multicolumn{3}{|c|}{ Currently certified as $\mathrm{OCN}^{\circledR}$ or $\mathrm{AOCN}^{\circledR}$} \\
\hline Yes & 211 & 56 \\
\hline No & 145 & 38 \\
\hline No response & 24 & 6 \\
\hline \multicolumn{3}{|l|}{ Ever participated in ELNEC program } \\
\hline Yes & 69 & 16 \\
\hline No & 268 & 71 \\
\hline No response & 43 & 11 \\
\hline \multicolumn{3}{|l|}{ Current practice area } \\
\hline Staff or charge nurse & 148 & 39 \\
\hline Bedside or direct care nurse & 117 & 31 \\
\hline Clinical nurse specialist & 25 & 7 \\
\hline Other (e.g., manager, educator) & 85 & 22 \\
\hline No response & 5 & 1 \\
\hline \multicolumn{3}{|l|}{ Hospital type } \\
\hline Community, nonprofit & 215 & 57 \\
\hline University medical center & 72 & 19 \\
\hline Community, for profit & 40 & 11 \\
\hline County hospital & 17 & 5 \\
\hline Federal hospital & 7 & 2 \\
\hline Military hospital & 2 & 1 \\
\hline State hospital & 4 & 1 \\
\hline Other or no response & 23 & 7 \\
\hline
\end{tabular}

$\mathrm{N}=380$

AOCN ${ }^{\circledR}$-advanced oncology certified nurse; ELNEC-End-of-Life Nursing Education Consortium; $\mathrm{OCN}^{\circledR}$ —oncology certified nurse Note. Because of rounding, not all percentages total 100.

\section{Supportive Behaviors}

Twenty-four supportive behavior items were scored. Perceived supportive behavior impact scores (PSBIS) ranged from 6.51-19.55 (see Table 3). The top supportive behavior by impact score was allowing family members adequate time to be alone with the patient after death, followed by providing a peaceful bedside scene for family after the patient has died, allowing family unlimited access to the dying patient, and teaching family members how to act around the dying patient.

The bottom three supportive behavior items were having educational in-services on how to care for the dying patient, having a fellow nurse observe patients while the primary nurse "gets away," and having the physician meet in person with the family after the patient's death to offer support. Significant in all three of those supportive behavior items was that size scores for each item were relatively high, which indicated that oncology nurses felt those items were important; however, frequency scores for items were very low, which indicated they rarely occurred.

\section{Discussion}

Participants in the EOL survey were members of ONS and had an average of 18 years of nursing experience. Participants were highly educated in oncology nursing, with $65 \%$ having had oncology nursing certification at some time in their practice. The sample was randomly selected, geographically dispersed, and of a statistically significant size, so results can be generalized to ONS members who work in a hospital-based setting.

Similarities were found between the current study and the previous study of oncology nurses' perceptions of obstacles and supportive behaviors to EOL care (Beckstrand et al., 2009). Eight of the top 10 obstacles and 8 of the top 10 supportive behavior items identified by POIS and PSBIS in this study also were found to be in the top 10 items of the previous study. However, significant discrepancies also were found between the two studies.

Four obstacle items and four supportive behavior items ranked significantly different with the addition of frequency of occurrence data. For example, the highestranked obstacle by size in the 2009 study (having to deal with angry family members) decreased to eighth place by POIS. In addition, the 5th ranked obstacle in the 2009 study (doctors insisting on aggressive care) dropped to 11th. Two other obstacle items ranked higher with the addition of frequency of occurrence data, moving from 13th to 6th (nurse having to deal with distraught family while still providing care) and from 23rd to 14th (nurse knowing patient's poor prognosis before family) (Beckstrand et al., 2009). 


\begin{tabular}{|c|c|c|c|c|c|c|c|}
\hline \multirow[b]{2}{*}{ Obstacle } & \multicolumn{3}{|c|}{ Size } & \multicolumn{3}{|c|}{ Frequency } & \multirow[b]{2}{*}{ POIS } \\
\hline & $\overline{\mathbf{X}}^{\mathbf{a}}$ & SD & Rank & $\overline{\mathbf{X}}^{\mathbf{b}}$ & SD & Rank & \\
\hline Dealing with anxious family & 3.51 & 1.03 & 1 & 3.27 & 0.91 & 1 & 11.48 \\
\hline Family not accepting patient's poor prognosis & 3.54 & 0.98 & 2 & 2.89 & 0.93 & 4 & 10.23 \\
\hline $\begin{array}{l}\text { Called away to help with new admission or to help another } \\
\text { nurse }\end{array}$ & 3.51 & 1.09 & 4 & 2.89 & 1.1 & 5 & 10.14 \\
\hline $\begin{array}{l}\text { Families being overly optimistic despite patient's poor prog- } \\
\text { nosis }\end{array}$ & 3.43 & 1.1 & 6 & 2.78 & 0.94 & 6 & 9.535 \\
\hline $\begin{array}{l}\text { Family and friends who continually call the nurse wanting } \\
\text { an update on the patient's condition rather than calling the } \\
\text { designated family member }\end{array}$ & 3.36 & 1.25 & 7 & 2.77 & 1.13 & 7 & 9.312 \\
\hline $\begin{array}{l}\text { Nurse having to deal with distraught family while still provid- } \\
\text { ing patient care }\end{array}$ & 3.12 & 1.13 & 13 & 2.98 & 0.97 & 3 & 9.298 \\
\hline $\begin{array}{l}\text { Family not understanding consequences of aggressive treat- } \\
\text { ment (e.g., nausea, vomiting, diarrhea, anemia) }\end{array}$ & 3.3 & 1.16 & 11 & 2.58 & 0.97 & 8 & 8.514 \\
\hline Nurse having to deal with angry family members & 3.54 & 1.08 & 3 & 2.38 & 0.95 & 12 & 8.425 \\
\hline $\begin{array}{l}\text { Patient's family not wanting patient to be overly sedated from } \\
\text { pain medication }\end{array}$ & 3.35 & 1.21 & 8 & 2.38 & 0.93 & 13 & 7.973 \\
\hline Doctors overly optimistic about survival & 3.08 & 1.22 & 14 & 2.52 & 0.99 & 10 & 7.76 \\
\hline Doctors insist on aggressive care & 3.47 & 1.4 & 5 & 2.23 & 1.07 & 16 & 7.738 \\
\hline $\begin{array}{l}\text { Intrafamily fighting about whether to continue or stop aggres- } \\
\text { sive treatment }\end{array}$ & 3.31 & 1.15 & 9 & 2.31 & 0.87 & 14 & 7.646 \\
\hline $\begin{array}{l}\text { Not enough time to provide high-quality EOL care because } \\
\text { nurse is trying to save patient's life }\end{array}$ & 3.07 & 1.23 & 15 & 2.47 & 1.09 & 11 & 7.583 \\
\hline Nurse knowing patient's poor prognosis before family & 2.4 & 1.4 & 23 & 3.04 & 1.09 & 2 & 7.296 \\
\hline Patient's pain difficult to control or alleviate & 3.3 & 1.3 & 10 & 2.18 & 0.93 & 17 & 7.194 \\
\hline Patient having too many visitors & 2.61 & 1.39 & 19 & 2.53 & 1.15 & 9 & 6.603 \\
\hline Poor unit design—no privacy for patient or family & 2.71 & 1.79 & 18 & 2.29 & 1.56 & 15 & 6.206 \\
\hline $\begin{array}{l}\text { Lack of nursing training and education in EOL care and family } \\
\text { grieving }\end{array}$ & 2.83 & 1.5 & 17 & 2.14 & 1.18 & 18 & 6.06 \\
\hline Employing life-sustaining measures at family request & 3.17 & 1.64 & 12 & 1.72 & 0.97 & 23 & 5.452 \\
\hline Continuing treatments that cause pain & 3 & 1.51 & 16 & 1.73 & 0.99 & 22 & 5.19 \\
\hline Dealing with cultural differences & 2.53 & 1.21 & 21 & 2.05 & 0.93 & 19 & 5.187 \\
\hline Not knowing what to say to grieving patient or family & 2.56 & 1.46 & 20 & 1.99 & 1.09 & 20 & 5.094 \\
\hline Family not with patient when patient is dying & 2.46 & 1.22 & 22 & 1.95 & 0.81 & 21 & 4.797 \\
\hline No support person (e.g., social worker, clergy) & 2.03 & 1.49 & 25 & 1.41 & 1.05 & 24 & 2.862 \\
\hline Limit grieving time for new admissions & 2.13 & 1.75 & 24 & 1.12 & 1.08 & 25 & 2.386 \\
\hline Restrictive visiting hours & 1.02 & 1.59 & 26 & 0.58 & 0.95 & 26 & 0.592 \\
\hline
\end{tabular}

a Size of obstacle responses ranged from 0 (not an obstacle) to 5 (extremely large).

${ }^{\mathrm{b}}$ Frequency of occurrence for obstacle responses ranged from 0 (never occurs) to 5 (always occurs).

c POIS is determined by the obstacle intensity $\bar{X}$ multiplied by obstacle frequency $\bar{X}$. 
Four supportive behavior items significantly increased in ranking after frequency of occurrence data were added to the study. Allowing families unlimited access to the dying patient rose from 14th to 3rd and teaching family members how to act around the dying patient increased from ninth to fourth. Having family members show appreciation for the care of patient increased from 15th to 7 th, and the nurse drawing on previous EOL experience moved from 23rd to 12th (Beckstrand et al., 2009).

\section{Obstacles}

Interestingly, four of the top eight obstacles regarding patients' families also had the component of emotion, as in dealing with anxious, overly optimistic, distraught, or angry family members. The other four top 10 items surrounding family issues regarded the family not accepting the poor prognosis, family and friends who continually call the nurse, family not understanding consequences of aggressive treatment, and the family not wanting the patient to be overly sedated. The data surrounding family issues at EOL are validated by other studies. Popejoy, Brandt, Beck, and Antal (2009) identified that helping the patient through the dying process also involved helping the family, and that the family became the patient. Waldrop (2007) found that caregiver grief during EOL care included the components of heightened responsiveness, anxiety, depression, anger, and fear. Similarly, the obstacles of family not understanding life-saving treatment, frequent telephone calls from family, and dealing with distraught and angry family members were found among critical care and emergency room nurses (Beckstrand \& Kirchhoff, 2005; Beckstrand et al., 2008).

Inadequate time to provide high-quality EOL care was identified in the third (being called away to help with another nurse) and fifth (family and friends continually call the nurse) most commonly rated obstacles. However, among critical care and emergency nurses, lack of time was the most highly rated obstacles (Beckstrand et al., 2006; Beckstrand \& Kirchhoff, 2005; Beckstrand et al., 2008). The issue of limited time for offering compassionate and comprehensive EOL care among oncology nurses also was identified by Pavlish and Ceronsky (2007).

Other highly rated obstacle items were the nurse being called away from the patient (7th), and two issues regarding physicians, doctors being overly optimistic about survival (10th), and doctors insisting on aggressive care (11th). Critical care nurses (Beckstrand \& Kirchhoff, 2005) also identified physicians being overly optimistic about survival as an important obstacle but ranked "differing opinions among physicians" and "physicians being evasive" as even higher obstacles.

Of note, although previous research identified lack of communication as a major obstacle (Beckstrand et al., 2006; Cherlin et al., 2005; Heyland et al., 2006; Popejoy et al., 2009; Royak-Schaler et al., 2006), none of the top 10 items in the current study involved communication, perhaps because this highly experienced group of oncology nurses has developed the skills to better communicate with patients, families, and healthcare providers. For example, the communication problem of the nurse knowing the prognosis before the patient was 2 nd by frequency of occurrence but 23rd by mean size of item. Although that obstacle occurs frequently, nurses did not find it to be difficult, possibly because the nurses in this sample were aware that their patients may not be ready to accept a poor prognosis and they may have wanted the patients to remain hopeful.

The need for or lack of EOL care training for nurses also was identified in previous studies (Caton \& Klemm, 2006; Coyne et al., 2007; Deffner \& Bell, 2005; Kruse, Melhado, Convertine, \& Stecher, 2008; Lange et al., 2008; Mallory, 2003; White et al., 2001). However, in this study, three obstacles related to EOL education for nurses were identified but ranked in the bottom half of the list by POIS. Each was similarly ranked by size mean, frequency mean, and POIS. These educationrelated obstacles were lack of nursing training and education in EOL care and family grieving (18th), dealing with cultural differences (21st), and not knowing what to say to a grieving patient or family (22nd). The lower rankings for those items might be explained by the fact that the average years worked in oncology by this sample of oncology nurses was 12.5 years, whereas less experienced nurses might have found these items to be greater obstacles. In addition, although those obstacles were not ranked higher by POIS, many obstacles that did rank higher also might be improved by better EOL training, such as those related to distraught, angry, and anxious family members and items related to the family not understanding the plan of care or prognosis.

\section{Supportive Behaviors}

Significantly higher impact scores were reported in supportive behavior items than in obstacle items. Supportive behavior items likely received higher scores because nurses are more in control of these behaviors, particularly regarding how frequently each occurs.

The top four supportive behavior items by PSBIS indicated the importance nurses placed on caring for the grieving family once a patient died. The top two items, allowing family members adequate time alone with the patient after death and providing a peaceful bedside scene for family, related to behaviors the nurse could facilitate. The supportive behavior items ranked third (allowing family members unlimited access to dying patient) and fourth (teaching family members how to 
act around the dying patient) also were items the nurse could control for the family.

The top supportive behaviors identified by critical care (Beckstrand \& Kirchhoff, 2005) and emergency room nurses (Beckstrand et al., 2008) were similar to the oncology nurses in this study and included allowing family members adequate time alone with the patients after death; providing a peaceful, dignified bedside scene; and teaching family members how to act around the dying patient. Albinsson and Strang (2003)

\section{Table 3. Statistics and Rank by Size and Frequency, and Perceived Supportive Behavior Impact Score (PSBIS) for Supportive and Helpful Behaviors in End-of-Life Care}

\begin{tabular}{|c|c|c|c|c|c|c|c|}
\hline \multirow[b]{2}{*}{ Behavior } & \multicolumn{3}{|c|}{ Size } & \multicolumn{3}{|c|}{ Frequency } & \multirow[b]{2}{*}{ PSBIS } \\
\hline & $\overline{\mathbf{X}}^{\mathrm{a}}$ & SD & Rank & $\overline{\mathbf{X}}^{\mathbf{b}}$ & SD & Rank & \\
\hline $\begin{array}{l}\text { Allowing family members adequate time alone with the patient after } \\
\text { death }\end{array}$ & 4.59 & 0.61 & 1 & 4.26 & 0.93 & 1 & 19.55 \\
\hline Providing peaceful bedside scene for family after patient has died & 4.5 & 0.71 & 5 & 4.02 & 0.95 & 2 & 18.09 \\
\hline Allowing families unlimited access to dying patient & 4.22 & 1.05 & 14 & 3.88 & 1.07 & 3 & 16.37 \\
\hline $\begin{array}{l}\text { Teaching family members how to act around the dying patient, such } \\
\text { as saying to them, "She can still hear ... it's okay to talk to her." }\end{array}$ & 4.33 & 0.76 & 9 & 3.62 & 0.98 & 4 & 15.67 \\
\hline Having social work or palliative care as part of the team & 4.55 & 0.68 & 2 & 3.41 & 1.2 & 5 & 15.52 \\
\hline Doctors agree about direction of care & 4.51 & 0.69 & 4 & 3.13 & 0.95 & 7 & 14.12 \\
\hline Having family members show appreciation for care of patient & 4.22 & 0.9 & 15 & 3.32 & 0.99 & 6 & 14.01 \\
\hline Family accepts patient is dying & 4.53 & 0.65 & 3 & 3.03 & 0.78 & 9 & 13.73 \\
\hline $\begin{array}{l}\text { Social work or palliative care established rapport with family before } \\
\text { patient is actively dying }\end{array}$ & 4.39 & 0.75 & 8 & 3.03 & 1.18 & 10 & 13.3 \\
\hline Having a fellow nurse give words of support after death of patient & 4.39 & 0.79 & 7 & 2.8 & 1.19 & 11 & 12.29 \\
\hline Having experienced RNs model end-of-life care for new RN & 4.4 & 0.79 & 6 & 2.76 & 1.25 & 12 & 12.14 \\
\hline Nurse draws on previous end-of-life experience & 3.78 & 1.04 & 23 & 3.1 & 1.08 & 8 & 11.72 \\
\hline Having time to educate family about dying process & 4.27 & 0.77 & 11 & 2.69 & 0.97 & 13 & 11.49 \\
\hline Unit schedule allowing for continuity of care & 4.25 & 0.84 & 13 & 2.64 & 1.19 & 14 & 11.22 \\
\hline Talking with patient about his or her own feelings about dying & 4.19 & 0.82 & 16 & 2.55 & 1.01 & 16 & 10.68 \\
\hline $\begin{array}{l}\text { Having one family member be the contact person regarding } \\
\text { patient information }\end{array}$ & 4.33 & 0.81 & 10 & 2.45 & 0.97 & 17 & 10.61 \\
\hline Having a fellow nurse give physical support after death of patient & 4.02 & 1.09 & 18 & 2.6 & 1.28 & 15 & 10.45 \\
\hline Unit designed so family can grieve in private & 4.27 & 0.85 & 12 & 2.36 & 1.51 & 20 & 10.08 \\
\hline Support staff gathers necessary paperwork after patient's death & 3.94 & 1.13 & 19 & 2.4 & 1.52 & 19 & 9.46 \\
\hline Having family physically help with care of dying patient & 3.72 & 1.06 & 24 & 2.44 & 1.04 & 18 & 9.08 \\
\hline $\begin{array}{l}\text { Having a support person outside of work to listen after death } \\
\text { of patient }\end{array}$ & 3.83 & 1.22 & 21 & 2.36 & 1.46 & 21 & 9.04 \\
\hline Educational in-services on how to care for dying patients & 4.09 & 0.94 & 17 & 1.9 & 1.2 & 23 & 7.77 \\
\hline Fellow nurse covers to allow you to "get away" & 3.78 & 1.07 & 22 & 1.94 & 1.34 & 22 & 7.33 \\
\hline $\begin{array}{l}\text { Having physician meet in person with family after patient's death } \\
\text { to offer support }\end{array}$ & 3.85 & 1.13 & 20 & 1.69 & 1.2 & 24 & 6.51 \\
\hline
\end{tabular}

a Size of helpful behavior responses ranged from 0 (not a help) to 5 (extremely helpful).

${ }^{b}$ Frequency of occurrence for helpful behavior responses ranged from 0 (never occurs) to 5 (always occurs).

' $\mathrm{PSBIS}$ is determined by the behavior size $\bar{X}$ multiplied by behavior frequency $\bar{X}$. 
and McMillen (2008) also identified providing support for the family at the time of death and afterward as an important supportive nursing behavior.

Social work or palliative care team members could help the family accept the anticipated death of the patient. Having social workers as part of the team had a size ranking of two but a frequency of occurrence ranking of five, indicating it did not occur as often as oncology nurses would have liked.

Literature supported the need for greater training and selection of mentors (Caton \& Klemm, 2006); improved EOL education (Caton \& Klemm, 2006; Coyne et al., 2007; Mallory, 2003); and improved EOL competencies in communication, comfort care, and dealing with families (White et al., 2001). However, in the current study, the supportive behavior items "having experienced RNs model EOL care for newer RNs" and "educational inservices on how to care for dying patients" ranked 11th and 22nd, respectively. The low ranking in this study might be explained by the demographics of the survey. Nurses selected for the study were all members of ONS and most had been oncology nursing certified at some point, which possibly indicated a higher degree of professionalism, experience, and knowledge.

\section{Implications for Nursing}

The purpose of this study was to determine impact scores for obstacle and supportive behavior items in EOL care as perceived by hospital-based oncology nurses. Results indicate that nurses understand the importance of family issues and attitudes in improving EOL care. Recommendations to improve communication, provide effective education, and promote teamwork can be made as a result of this study and could improve EOL care for patients and their families.

\section{Improve Communication Between the Family, Nurse, and Patient}

Traditionally, a patient's preferences regarding EOL have been communicated via advanced directives (e.g., living wills, DNR orders). However, advanced directives have not always been effectively communicated to the healthcare team, particularly in cases where the patient has been transferred among facilities.

To address that problem, physician orders for lifesustaining treatment (POLST) (also known in some states as medical orders for life-sustaining treatment) have been developed (Mitchell, 2011). POLST seek to clarify and solidify wishes already expressed in a living will or advanced directive. The goal is to transfer a patient's wishes into medical orders via a brightly colored form that addresses artificial nutrition, pain management, antibiotics, comfort measures, and other medical interventions.
POLST programs are meant to complement, not replace, advanced directives, and are based on EOL conversations with a healthcare provider. Because oncology nurses in this study identified several areas where communication between patients, families, and caregivers was less than optimal, the use of POLST or a similar tool is highly recommended.

\section{Provide Effective Education}

The End-of-Life Nursing Education Consortium (ELNEC) program was shown to be effective in improving EOL care education with oncology nurses (Coyne et al., 2007). The ELNEC program provides oncology nurses with the tools and training to effectively provide palliative care to patients and families. The curriculum includes cultural considerations, communication, and preparation for death, all of which were identified in the current study as barriers to EOL care. Oncology nurses and their patients, as well as patients' families, would benefit from nurses receiving more education as provided by the ELNEC program.

\section{Promote a Team Approach}

Oncology nurses in this study understood that having social workers, palliative care providers, physicians, and nurses on the same team could improve EOL care. The act of dying is complicated for the patient and family, as it involves intense physical and emotional work. Only if participants work together can this transition from life to death be a more positive experience.

\section{Conclusions}

This study validates what many oncology nurses have experienced-that dealing with the family is vital to the care of patients with cancer. As high-quality EOL care continues to be a pressing issue for patients with cancer and their families, medical professionals must access the expertise and input of hospital-based oncology nurses. By carefully considering their experience, concerns, and recommendations, the most compassionate care can be possible. Only then will medical professionals, patients, and their families realize the optimal outcomes they desire.

Renea L. Beckstrand, PhD, RN, CCRN, CNE, is an associate professor in the College of Nursing at Brigham Young University, Joan Collette, MS, FNP-C, is a family nurse practitioner at the Central Utah Oncology Clinic, Lynn Callister, PhD, RN, FAAN, is an emeritus professor in the College of Nursing at Brigham Young University, and Karlen E. Luthy, DNP, FNP-C, is an assistant professor in the College of Nursing at Brigham Young University, all in Provo, UT. This study was funded, in part, by an internal research grant from the College of Nursing at Brigham Young University. Beckstrand can be reached at renea@byu. edu, with copy to editor at ONFEditor@ons.org. (Submitted July 2011. Accepted for publication November 8, 2011.)

Digital Object Identifier: 10.1188/12.ONF.E398-E406 


\section{References}

Albinsson, L., \& Strang, P. (2003). Differences in supporting families of dementia patients and cancer patients: A palliative perspective. Palliative Medicine, 17, 359-367. doi:10.1191/0269216303pm669oa

American Cancer Society. (2012). Cancer facts and figures, 2012. Retrieved from http://www.cancer.org/acs/groups/content/@epi demiologysurveilance/documents/document/acspc-031941.pdf

American Society for Pain Management Nursing. (2003). ASPMN position statement on pain management at the end of life. Retrieved from http:/ / www.aspmn.org/Organization/documents/End ofLifeCare.pdf

Beckstrand, R.L., Callister, L.C., \& Kirchhoff, K.T. (2006). Providing a "good death": Critical care nurses' suggestions for improving end-of-life care. American Journal of Critical Care, 15, 38-45.

Beckstrand, R.L., \& Kirchhoff, K.T. (2005). Providing end-of-life care to patients: Critical care nurses' perceived obstacles and supportive behaviors. American Journal of Critical Care, 14, 395-403.

Beckstrand, R.L., Moore, J., Callister, L., \& Bond, A.E. (2009). Oncology nurses' perceptions of obstacles and supportive behaviors at the end of life. Oncology Nursing Forum, 16, 446-453. doi:10.1188/09 .ONF.446-453

Beckstrand, R.L., Smith, M.D., Heaston, S., \& Bond, A.E. (2008). Emergency nurses' perceptions of size, frequency, and magnitude of obstacles and supportive behaviors in end-of-life care. Journal of Emergency Nursing, 34, 290-300. doi:10.1016/j.jen.2007.09.004

Braun, M., Gordon, D., \& Uziely, B. (2010). Associations between oncology nurses' attitudes toward death and caring for dying patients [Online exclusive]. Oncology Nursing Forum, 37, E43-E49. doi:10.1188/10.ONF.E43-E49

Bray, F., Jemal, A., Grey, N., Ferlay, J., \& Forman, D. (2012). Global cancer transitions according to the human development index (20082030): A population-based study. Lancet, 13, 790-801. doi:10.1016/ S1470-2045(12)70211-5

Cassel, C.K., \& Demel, B. (2001). Remembering death: Public policy in the USA. Journal of the Royal Society of Medicine, 94, 433-436.

Caton, A.P., \& Klemm, P. (2006). Introduction of novice oncology nurses to end-of-life care. Clinical Journal of Oncology Nursing, 10 604-608. doi:10.1188/06.CJON.604-608

Cherlin, E., Fried, T., Prigerson, H.G., Schulman-Green, D., JohnsonHurzeler, R., \& Bradley, E.H. (2005). Communication between physicians and family caregivers about care at the end of life: When do discussions occur and what is said? Journal of Palliative Medicine, 8, 1176-1185. doi:10.1089/jpm.2005.8.1176

Coyne, P., Paice, J.A., Ferrell, B.R., Malloy, P., Virani, R., \& Fennimore, L.A. (2007). Oncology End-of-Life Nursing Education Consortium training program: Improving palliative care in cancer. Oncology Nursing Forum, 34, 801-807. doi:10.1188/07.ONF.801-807

Cramer, C.F. (2010). To live until you die: Quality of life at the end of life. Clinical Journal of Oncology Nursing, 14, 53-56. doi:10.1188/10 .CJON.53-56

Deffner, J.M., \& Bell, S.K. (2005). Nurses' death anxiety, comfort level during communication with patients and families regarding death, and exposure to communication education: A quantitative study. Journal for Nurses in Staff Development, 21(1), 19-23.

Heyland, D.K., Dodek, P., Rocker, G., Groll, D., Gafni, A., Pichora, D., ... Lam, M. (2006). What matters most in end-of-life care: Perceptions of seriously ill patients and their family members. Canadian Medical Association Journal, 174, 627-633. doi:10.1503/cmaj.050626

Kochanek, K.D., Xu, J., Murphy, S.L., Miniño, A.M., \& Kung, H. (2011). Deaths: Preliminary data for 2009. National Vital Statistics Reports, 59(4), 1-51. Retrieved from http://www.cdc.gov/nchs/ data/nvsr/nvsr59/nvsr59_04.pdf

Kruse, B.G., Melhado, L.W., Convertine, L., \& Stecher, J. (2008). Evaluating strategies for changing acute care nurses' perceptions on end-of-life care. American Journal of Hospice and Palliative Care, 25, 389-397. doi:10.1177/1049909108322368

Lange, M., Thom, B., \& Kline, N.E. (2008). Assessing nurses' attitudes toward death and caring for dying patients in a comprehensive cancer center. Oncology Nursing Forum, 35, 955-959. doi:10.1188/08 .ONF.955-959

Mallory, J.L. (2003). The impact of a palliative care educational component on attitudes toward care of the dying in undergraduate nursing students. Journal of Professional Nursing, 19, 305-312. doi:10.1016/ S8755-7223(03)00094-2

McMillen, R.E. (2008). End of life decisions: Nurses perceptions, feelings and experiences. Intensive and Critical Care Nursing, 24, 251-259. doi:10.1016/j.iccn.2007.11.002

Mitchell, J.K. (2011). POLST complement advance directives to better honor patients' preferences for end-of-life care. ONS Connect, 26(1), 19.

Oncology Nursing Society \& Association of Oncology Social Work. (2010). Oncology Nursing Society and Association of Oncology Social Work joint position on palliative and end-of-life care. Retrieved from http://www.ons.org/publications/media/ons/docs/positions/ endoflife.pdf

Pavlish, C., \& Ceronsky, L. (2007). Oncology nurses' perceptions about palliative care. Oncology Nursing Forum, 34, 793-800. doi:10.1188/07 ONF793-800

Pavlish, C., \& Ceronsky, L. (2009). Oncology nurses' perceptions of nursing roles and professional attributes in palliative care. Clinical Journal of Oncology Nursing, 13, 404-412. doi:10.1188/09.CJON $.404-412$

Popejoy, L.L., Brandt, L.C., Beck, M., \& Antal, L. (2009). Intensive care unit nurse perceptions of caring for the dying. Journal of Hospice and Palliative Nursing, 11, 179-186. doi:10.1097/NJH.0b013e3181a1ac61

Royak-Schaler, R., Gadalla, S., Lemkau, J., Ross, D., Alexander, C., \& Scott, D. (2006). Family perspectives on communication with healthcare providers during end-of-life cancer care. Oncology Nursing Forum, 33, 753-760. doi:10.1188/06.ONF.753-760

Rutledge, D.N., Donaldson, N.E., \& Pravikoff, D.S. (2001). End-oflife care series. Part II. End-of-life care for hospitalized adults in America-Learnings from the SUPPORT and HELP studies. Online Journal of Clinical Innovations, 4.

Sawatzky, J.A. (1996). Stress in critical care nurses: Actual and perceived. Heart and Lung, 25, 409-417. doi:10.1016/S0147-9563(96) 80084-7

Singer, P.A., \& Bowman, K.W. (2002). Quality end-of-life care: A global perspective. BMC Palliative Care, 1, 4. doi:10.1186/1472-684X-1-4

Steinhauser, K.E., Clipp, E.C., McNeilly, M., Christakis, N.A., McIntyre, L.M., \& Tulsky, J.A. (2000). In search of a good death: Observations of patients, families, and providers. Annals of Internal Medicine, 132, 825-832.

SUPPORT Principal Investigators. (1995). A controlled trial to improve care for seriously ill hospitalized patients. The Study to Understand Prognoses and Preferences for Outcomes and Risks of Treatment (SUPPORT). JAMA, 274, 1591-1598. doi:10.1001/ jama.1995.03530200027032

Waldrop, D.P. (2007). Caregiver grief in terminal illness and bereavement: A mixed-methods study. Health and Social Work, 32, 197-206. doi:10.1093/hsw/32.3.197

White, K.R., Coyne, P.J., \& Patel, U.B. (2001). Are nurses adequately prepared for end-of-life care? Journal of Nursing Scholarship, 33 147-151. doi:10.1111/j.1547-5069.2001.00147.x

Yabroff, K.R., Mandelblatt, J.S., \& Ingham, J. (2004). The quality of medical care at the end-of-life in the USA: Existing barriers and examples of process and outcome measures. Palliative Medicine, 18 202-216. doi:10.1191/0269216304pm880oa 
Copyright of Oncology Nursing Forum is the property of Oncology Nursing Society and its content may not be copied or emailed to multiple sites or posted to a listserv without the copyright holder's express written permission. However, users may print, download, or email articles for individual use. 